\title{
Edith Stein's phenomenology of sensual and emotional empathy
}

\author{
Fredrik Svenaeus ${ }^{1}$ (D)
}

Published online: 7 November 2017

(C) The Author(s) 2017. This article is an open access publication

\begin{abstract}
This paper presents and explicates the theory of empathy found in Edith Stein's early philosophy, notably in the book On the Problem of Empathy, published in 1917, but also by proceeding from complementary thoughts on bodily intentionality and intersubjectivity found in Philosophy of Psychology and the Humanities published in 1922. In these works Stein puts forward an innovative and detailed theory of empathy, which is developed in the framework of a philosophical anthropology involving questions of psychophysical causality, social ontology and moral philosophy. Empathy, according to Stein, is a feelingbased experience of another person's feeling that develops throughout three successive steps on two interrelated levels. The key to understanding the empathy process á la Stein is to explicate how the steps of empathy are attuned in nature, since the affective qualities provide the energy and logic by way of which the empathy process is not only inaugurated but also proceeds through the three steps and carries meaning on two different levels corresponding to two different types of empathy: sensual and emotional empathy. Stein's theory has great potential for better understanding and moving beyond some major disagreements found in the contemporary empathy debate regarding, for instance, the relation between perception and simulation, the distinction between what is called low-level and highlevel empathy, and the issue of how and in what sense it may be possible to share feelings in the empathy process.
\end{abstract}

Keywords Edith stein.Phenomenology·Empathy·Philosophy of emotion - Lived body. Sympathy

Fredrik Svenaeus

fredrik.svenaeus@sh.se

1 Centre for Studies in Practical Knowledge, Department of Philosophy, Södertörn University, 141 89 Huddinge, Sweden 


\section{Introduction}

The significance of Edith Stein's theory of empathy has recently been brought to attention in cognitive science and neighbouring fields (Dullstein 2013; Jardine 2014, 2015; Svenaeus 2016; Szanto 2015; Vendrell Ferran 2015; Zahavi 2014), but many important aspects of her work regarding the nature and role of empathy in social cognition remain to be spelled out. My goal in this paper is to present in some detail the theory of empathy found in Stein's early philosophy, notably in the book Zum Problem der Einfühlung (short: the empathy book) published in 1917 (2008), but also by proceeding from complementary thoughts on bodily intentionality and intersubjectivity that we find in Beiträge zur philosophischen Begründung der Psychologie und der Geisteswissenschaften (short: Beiträge) published in 1922 (2010). In these works Stein puts forward an innovative theory of empathy, which is developed in the framework of a philosophical anthropology involving psychophysical causality, social ontology, and moral philosophy. Her main sources of inspiration are Edmund Husserl (1976) and Max Scheler (2005), but the phenomenological empathy theory she ends up with is different from theirs and also from other influential theories in the historical and contemporary debates (overviews of empathy theories are found in: Coplan and Goldie 2011; Decety 2012).

Stein's suggestion for how to envisage the phenomenon of empathy takes its starting point in the idea that empathy is a way of feeling oneself into the experiences of the other person ("sich einfühlen"). As I will develop and elaborate upon below, this basic aspect of the empathy process is not always acknowledged when phenomenologists claim empathy to be a direct and basic way of perceiving and understanding the other person (eg. Zahavi 2011). Stein herself takes the feeling aspects of empathy to be very much granted by the terminology of "Einfühlung" and therefore does not openly address the topic of how the phenomenology of different types of feelings, which is found in the two works I have referred to, is linked to her phenomenology of empathy. I will aim to remedy this lack by making explicit and systematizing Stein's philosophy of feelings as it appears in her account of empathy. I find this endeavour worthwhile, since Stein's philosophy of feelings, in the same way as her theory of empathy, is very much in tune with contemporary research on feelings in phenomenology and cognitive science although outlined in a different terminology (Colombetti 2014; Svenaeus 2016). By presenting Stein's account of empathy as the feeling-based process she regarded it to be, I hope to make obvious how rich, nuanced and significant to the contemporary discussion her theory is.

Empathy, according to Stein, is an experience of another person's experience. The experiences ("Erlebnisse") that she considers to belong to empathy are various forms of feelings (I will use the term "feeling" in an all encompassing way including subspecies of various types of feelings such as "sensual feelings" "moods" and "emotions"). They are perceptual and imaginative feelings on the part of the empathizer and feelings that are expressed bodily on the part of the empathee (the person who is empathized with). Specifically, as I will attempt to show, Stein takes empathy to be a three-step process in which the experience of the other person (the empathee) (1) emerges to the empathizer as an experience had by the empathee, the empathizer then (2) follows the experience of the empathee through, in order to (3) return to a more comprehensive understanding of the meaning of the experience had by the empathee (Stein 2008: 18-19). 
The key to understanding the empathy process á la Stein is to explicate how the three steps of empathy are attuned (feeling based) in nature, since the affective qualities provide the energy and logic by way of which the empathy process is not only inaugurated but also proceeds through the three successive steps and carries meaning on two interrelated levels - the levels of sensual empathy and emotional empathy. In this paper I will use the terms "step" or "stage" to refer to that which Stein calls three different "Vollzugsstufen" of empathy, whereas the term "level" will be reserved for the difference between sensual empathy and emotional empathy (the term Stein most often employs here is "Schichte," referring to feelings with various depth, more about this below). I will also refer to sensual versus emotional empathy as two different types of empathy enacted on the two above-mentioned levels: emotional empathy always presupposing sensual empathy.

\section{Stein's theory and contemporary empathy research}

Let me now offer the quote most often provided when Stein's theory of empathy is introduced and from which I have already distilled some of her main points:

Now to empathy itself. Here, too [as in memory, expectation, or imagination, $m y$ addition], we are dealing with an act that is original in the sense of being a present experience but non-original as regards its content. ... When it suddenly appears before me it faces me as an object (for instance, the sadness I "read" in the other's face). But when I inquire into its implied tendencies (when I try to bring the other's mood to clear givenness to myself), the experience is no longer an object for me, but has pulled me into it. I am now no longer turned towards the experience, but instead I am turned towards the object of the experience. I am at the subject of the original experience, at the subject's place, and only after having fulfilled a clarification of the experience does it appear to me as an object again.

Consequently, we have in all considered cases when experiences [of other persons, my addition] are appearing to us three stages or modalities of accomplishment, even though in each concrete case not all of the three stages are accomplished, but we often are satisfied with stage one or stage two: 1. the emergence of the experience, 2. the fulfilling explication, and 3. the comprehensive objectification of the explicated experience. (Stein 2008: 18-19)

Empathy, according to Stein, is similar to perception in presenting something - the experiences of the other person - in an unmediated way, but dissimilar to perception and similar to other forms of experiences, such as imagination, in that the meaning content of the experience is not given directly to the empathizer. The terms Stein uses to get hold of this distinction is that something appears to consciousness in an "original" or "nonoriginal" way (Stein 2008: 15). Regarding the content — "Gehalt" —of an act of consciousness that appears originally as opposed to non-originally, the term Stein (and Husserl, the work of whom is the main inspiration for Stein in the empathy book) often uses to stress the first form is "leibhaft gegenwärtig", or "leibhaft gegeben", that is, 
"given in bodily presence" (e.g. Stein 2008: 16, 31). When, for instance, I remember the way my dinner of yesterday tasted, I am making something present in my experience in a kind of secondary way, because the experience in question is brought back in memory and is not there in its actuality (the way the dinner tasted then). Stein's point is that the empathy experience is non-original in a way that is similar to the act of remembrance, but with the important difference that the content of the experience has never been bodily present to me but is present as such only to the other person that I am empathizing with. The term Stein will use to distinguish this special form of non-originality, which is peculiar to empathy, is "con-original" ("Konoriginarität").

Stein discerns two interconnected types of empathy, by which the three step-process can be enacted on two different levels. In the contemporary empathy discussion researchers often distinguish between low-level (basic) versus high-level (re-enactive) empathy (for an overview, see Coplan and Goldie 2011). Low-level empathy is most often understood to be more or less automated in character whereas high-level empathy consists in an attempt to imagine how it would feel to be in the other person's shoes (or even how it would feel to be her). The advantage of Stein's theory is that we could understand this distinction to be either about step-one and step-two empathy on the sensual or emotional level, or about the difference between two different but interrelated types of empathy (sensual and emotional). In this way Stein's theory allows for a more nuanced and complete account of the empathy process than most contemporary theories do.

In the second step of Stein's model (on both levels) we view the transformation of something merely perception-like into something that is also imagination-like, proceeding through the third step to something that is perception-with-imagination-like. The key to understanding this dynamic drift of the empathy process is, I believe, to underline the feeling-based aspects of all three steps as they typically lead into and reinforce each other. Stein writes that steps two and three do not always occur in the empathic process, but the most enlightening interpretation of her position on this point is that other thoughts and feelings we are having and/or aspects of the situation we find ourselves in may voluntarily or involuntarily stop us from proceeding from step one to steps two and three in the process (Stein 2008: 19, 26). In Stein's view, experiences of experiences of other persons which because of such blocks do not lead to any fulfilling explications could still count as empathy if they give us at least a basic understanding of the experiences the other person is having (step-one empathy).

In addressing the contemporary scene one should be aware that Stein wants her phenomenology of empathy to accomplish two things, which roughly square with providing answers to two central questions guiding empathy research from her time up to the present day, namely, "How can one know what another person is thinking and feeling?" and "What leads one person to respond with sensitivity and care to the suffering of another?" (Batson 2009: 3; for overviews of contemporary empathy research, see Coplan and Goldie 2011; Decety 2012). Whereas the answers to the first question will employ empathy as a main road to sociality, the answers to the second are also engaged with stressing empathy as one of the key constituents in an ethics of care (Calcagno 2014: 90 ff.).

Stein's book on empathy is a shortened version of her doctoral dissertation, which additionally contained not only a first part surveying the concept of empathy in 
eighteenth- and nineteenth-century philosophy, but also a fifth, sixth and seventh part about empathy as a social, ethical and aesthetic phenomenon respectively (Stein 2008: $\mathrm{xx}$-xxi). Nobody knows exactly what thoughts Stein put into these parts, because all existing copies of the dissertation are gone (Stein 2008: xxi). What remains is the published book from 1917 containing part two on the structure of the empathic act, part three on the lived body and part four on the concept of the person. In these published parts Stein makes clear that her overall aim is not only to study the structure of empathic experience but also the issues of what it means to be a person in a social context and how we ought to live together in the world. These questions are addressed in the second part of Beiträge dealing with the being-together of persons in various manners (important distinctions are made between the inauthentic forms of "Masse" and "Gesellschaft" on the one hand and the authentic communal being of a "Gemeinschaft" on the other) (Stein 2010: 218 ff.). Stein's overarching goal in both works appears to be no less than to develop a moral philosophy built on hierarchies of values that we encounter through feeling and acting together with other persons in the world. In this regard, her philosophical project is very similar to Scheler's, who was more interested in sympathy (love) than in empathy as such (Scheler 2009).

Stein's attempt to address both of Batson's question makes her theory of empathy slightly ambiguous as concerns what types of experience should count as empathy in the three-step, two-level model referred to above. Is it enough that I feel and understand the experiences that the person in front of me is undergoing (step one), or must I also feel alongside the other person in the sense of somehow joining her feelings (step two) in order for my experience to count as empathy? As I pointed out above, when first defining empathy and separating it from other forms of experiences in her book Stein settles with the first alternative (Stein 2008: 11-20), but in the ensuing analysis she clearly stresses that it is exactly the feeling in the footsteps of the other person which distinguishes the act of empathy from other experiences (Stein 2008: 21-25).

The feeling alongside (in the footsteps of) the other in empathy is neither to be confused with feeling together in the sense of having a mutual experience of the same thing (what Stein in Beiträge calls "Gemeinschaftserlebnisse"), nor with what Scheler calls "Einsfühlung" (feeling-at-one-with-the-other) (Stein 2008: 25-29). It is also not to be confused with that which both Stein and Scheler names sympathy ("Sympathie" or "Mitfühlen"), which is the empathizer's feeling of care for the empathee (Stein 2008: 24-25). Empathy is neither a matter of sharing the experiences (feelings) of the empathee in the strict sense, nor is it necessary a compassionate feeling for her. As we will see, sympathy in Stein requires empathy through all three steps and on both levels to be in place, since it is a caring about the other person in and through getting to know her experiences and personality by way of empathy (possibly in combination with other ways of getting to know her, such as verbal communication) (Stein 2008: 102-104, 116-130). In such cases, the empathy process is not only motivated by a care for the wellbeing of the other person (a common way of linking sympathy to empathy, see Jacob 2012), but is also employed as a high road to getting to know and caring for a specific person (Svenaeus 2015).

The steps that Stein discerns in the empathy process could be reiterated - step three could serve as a new step one on a higher level - such as happens when sensual empathy proceeds to become emotional empathy, as I will show below. The steps could also, however, be supplemented by other ways of engaging with the other person, such 
as talking to her or starting to do something for/to her or together with her. These acts will transform empathy into communication- and/or action-based forms of intersubjectivity that Stein explores more in detail in the second part of Beiträge on communal being (Stein 2010: $110 \mathrm{ff}$.). However, even though Stein restricts the empathy experience to the model specified above - steps that do not include conversation and coordinated actions between the parties - a form of tacit communication is arguably present already in the empathy process, provided the empathee recognizes that she is being empathized with and therefore directs her expressive behaviour towards the empathizer in the process (Jardine 2015). And the empathic feeling alongside the experiences of the other person will be at work also in many "empathy plus" forms of human interaction, which, in addition to feeling and understanding the experiences of the other person, also involve talking and acting together in the world. Indeed, empathy, at least in the step-one sense, needs to be at work in such cooperative experiences, since the first person must feel and know that the other person is doing the same thing he is doing, and, reciprocally, in order for the cooperation to be precisely a joint endeavour (Stein 2010: 156, 162, 202; on sociality in Stein, see Szanto 2015).

Many contemporary so called simulation-based accounts of empathy proceed from the idea that the empathizer imagines what it would be like to be in the empathee's shoes without the empathee necessarily being present to the empathizer when empathizing (Goldie 2000; Goldman 2006; Stueber 2006). In this way one could empathize not only with persons who are not physically present in the room, but possibly with the dead or with fictional characters in a book. In contrast to this, the examples of empathy Stein discusses are all based on the perceptual emergence of the other person in front of me. According to Stein, this is because all forms of empathy are put in motion by lived bodily expressions addressing themselves to the empathizer (humans or other animals expressing feelings and moving, see Stein 2008: 76 ff.). As I will develop below, all cases of empathy are basically sensual in character, meaning they are bodily felt experiences of other living bodies. Such an empathy theory does not disqualify the role of literature or human imagination in gaining a deeper understanding of other persons, it only denies that what I am doing when I am imagining what my friend would think about this book that I am reading, or, what a character in the book would think about me, are cases of empathy.

Stein does not consider the examples of painted pictures or photographs displaying living bodies, although such examples originally served to illustrate the process of Einfühlung in the German tradition she is working in (for instance the empathy theory of Theodor Lipps, see Coplan and Goldie 2011). Even more pressing examples of technologically-mediated empathy are contemporary ways of encountering other persons by way of telephone or Skype conversations in which the voice or/and visual experience of the other's body is present in a live conversation with her. In my view, Stein's theory is open to interpret such encounters in terms of empathy. As a matter of fact, to deny the presence of empathy in telephone or Skype conversations would be to deny that such forms of human communication are shared, joint endeavours in the first place. As pointed out above, empathy, at least in the step-one sense, needs to be at work in all cooperative experiences, since the first person must feel and know that the other person is doing the same thing he is doing, and, reciprocally, in order for the cooperation to be precisely a joint endeavour (Szanto 2015). In addition to such presence of step-one empathy it would also be possible for an empathizer to join into step-two 
empathy if, for instance, the person she is speaking to and possibly also watching on the screen suddenly falls into tears for one reason or the other.

\section{Sensual empathy}

Stein develops a phenomenological theory according to which certain types of feelings involve knowledge and judgements about things, persons and situations in the world, notably about how they are to be evaluated and cherished (Vendrell Ferran 2015). Her phenomenology of feelings and values is deeply influenced by Scheler's philosophy on this point (Scheler 2005, 2009), but it is also remarkably close to contemporary positions in cognitive science and analytical philosophy assigning fundamental importance to affectivity as concerns perception, knowledge and action (Colombetti 2014; Goldie 2000).

Stein begins with the feelings that are basic to all forms of perceptions and which involve bodily experience in a more obvious sense (see notably the first part of Beiträge: Stein 2010: 13 ff.). These "sensual feelings" (Stein names them "Gefühlsempfindungen" or "sinnliche Gefühle") have not reached the cognitive level of fully formed judgements about the state of things in the world, but yet they display a kind of evaluation of the present state of the organism and its surroundings:

The pleasantness of a savoury dish, the agony of a sensual pain, the comfort of a soft garment are noticed where the food is tasted, where the pain pierces, where the garment clings to the body's surface. However, sensual feelings are not only there but at the same time also in me; they issue from my ego. (Stein 2008: 65)

The ego ("das Ich") that Stein speaks about here is a fleshy self that is constituted (brought into being) and constitutes (creates) meaning as a lived body ("Leib"). It is not a transcendental ego in the Husserlian sense, a dimension of consciousness that Stein refers to as the domain of the pure ego ("das reine Ich"), but an ego (we may here also use the terminology of selfhood) that takes on empirical existence precisely through having sensual, bodily feelings. These feelings anchor the self in a body and by way of this anchoring make possible the having of a world:

It is possible to conceive of a subject living only in theoretical acts having an object world facing it without ever becoming aware of itself and its consciousness, without "being there" for itself. But this is no longer possible as soon as this subject not only perceives, thinks, etc., but also feels. For as it feels it experiences not only objects but also itself. It experiences feelings as coming from "the depth of its ego". This also means that this "self-experiencing" ego is not the pure ego, since the pure ego has no depth. The ego that is experienced in feeling, however, has levels of various depths that are revealed when feelings pour out of them. (Stein 2008: 117)

The relation between the lived personal body and its world is revealed already on the level of sensual feelings that are felt in the body and thus separate the lived body from the surrounding world. By offering a place and space for the lived body, these sensual 
feelings also make the world appear to a self by identifying things that matter to it outside of its experienced borders. In Beiträge, Stein refers to this difference as the difference between "ichliche" (egoish) and "ichfremde" (ego foreign) experiences - a more common terminology today would be inner and outer perception-but the crucial point is that Stein takes this difference and the constitutive power it carries to rely on sensual feelings (Stein 2010: 18, 67, 91-93).

Close to sensual feelings are the feelings Stein names "Gemeingefühle", "Lebensphänomene", or "Lebensgefühle", such as feeling vigorous or sluggish, awake or tired, young or old, or healthy or ill (Stein 2008: 65, 86, 93). These general feelings of aliveness reveal the entire lived body as being more or less full or empty of life energy, and they also provide the experienced world with a corresponding attuned quality. Stein wants to separate general feelings from moods ("Stimmungen") by arguing that the latter do not make themselves known within the domains of the lived body: they are felt only in the world and not in the self, so to speak; but it is hard to find any convincing arguments for this separation in her text, and she also admits that the two types of feelings may be hard to separate (Stein 2008: 65-66, 118-119). Do not anxiety, sadness, or joy - all of which are moods - announce themselves in revealing my embodiment and the state of the surrounding world, simultaneously, just as feeling vigorous or feeling ill do (Ratcliffe 2008)?

Coming back to empathy, Stein reserves a special name for a fundamental form of the phenomenon, which she thinks the previous research has neglected: sensual empathy ("Empfindungseinfühlung") (Stein 2008: 74-80). Sensual empathy is a process of recognition and understanding that takes place on the level of embodied existence when one lived body feels and perceives the presence of another lived body and follows its experiences through in a spontaneous manner. This process relies on what Stein calls fields of sensation ("Empfindungsfelder") through which the abovementioned sensual feelings ("Gefühlsempfindungen") protrude from the foreign lived body and draw me into its presence (Stein 2008: 74-75). When I see a hand resting on a table I see immediately that it is a lived body that is more or less tense or relaxed and that presses itself against the table more or less strongly in contrast to the book that lies beside it (Stein 2008: 75). But not only that, being a lived body myself, I then spontaneously follow the tenseness and pressing tendency of the foreign hand through with my own hand:

and in this manner of co-comprehension my hand moves itself (not in reality but "as if") into the place of the foreign one, into it, occupying its position and tendencies, and, now, feels its sensual feelings, not in an original way and not as being its own, but "with" the foreign hand precisely in the manner of the empathy process that we have earlier differentiated from our own experiences and every other kind of making present. (Stein 2008: 75)

Sensual empathy becomes even stronger in character when we watch foreign bodies move in a manner that is characteristic for human embodiment, and it is also facilitated by emotional expressions, particularly through facial expressions and gestures that humans show and perform. Stein notes that in this process it is enough that the foreign body is of a similar type as mine in order for sensual empathy to occur. For instance, I will recognize a child's hand as pressing on the table, although it is much smaller than 
mine, and even a dog's paw will do (Stein 2008: 76). As a matter of fact, in many cases I will immediately recognize the bodies of living creatures significantly different from the human type as living bodies, but I will have problems with particular aspects of bodily expression that are not similar enough to human body language, for instance, the tail-wagging of a dog (Stein 2008: 104). That is, I will recognize the lived quality of the dog's movements and expressions, but I will have problems "following through" that the tail-wagging is an expression of joy because humans do not have tails and do not express happiness in this way. Nevertheless, I may to some extent follow the wagging through, perhaps feeling in an empathic manner my whole body waggling. Or I may learn by experience that a wagging tail of a dog means that it is happy, proceeding through empathic awareness of other aspects of the dog's body language, which the wagging tail is then subsequently associated with.

\section{The meanings of "con-original" in Stein}

The distinction between recognizing the lived body of the dog and having difficulties following through the tail-wagging as an expression of joy should be understood as the difference between step one and step two in Stein's empathy theory. The empathy process that enfolds itself in the manner of three successive steps consequently applies already in the case of sensual empathy. This was clear from the example of the hand in which I first see that the hand is a hand, which is tense and presses on the table (step one), and then follow this tenseness and pressing movement through (step two) in order to return to a more enlightened, or, rather, "enlived" perception of what the hand is and does (step three). At this point one could accuse Stein of not underlining the differences between the three steps of sensual empathy as they develop. In her examples she generally elaborates only on step-two sensual empathy (Stein 2008: 74-80), but it is clear from the way she formulates her examples that she wants to differentiate between the steps, because what is given in step one prescribes possibilities of step two that are not always fulfilled. The reason the prescribed possibilities are not carried through, according to Stein, is that the lived bodies of empathee and empathizer are of different types or that the empathizer is lacking the relevant experiences to be able to proceed. Not only do humans not have tails, children do not yet have all the experiences that are required to empathize with adults, and non-blind persons do not have the experiences one needs to fully empathize with someone who is blind (Stein 2008: 80).

These are very important insights and distinctions, and the way Stein inscribes the limits of empathy by separating the first step from the second in the empathy process already on the sensual, body-based level is to be applauded. (The distinction will be even more important on the level of emotional empathy, as we will see below.) Nevertheless, her accounts of the empathizer's experiences in sensual empathy do not sufficiently differentiate between what "con-original" must mean on the two steps, respectively (Stein 2008: 75, 79). In the first step, the distinction between my original sensual experience - of being embodied in a certain way and responding to a surrounding world - and the sensual pattern of the lived body of the other person - appearing in my field of sensations - must rely on a general contrast. The sensual feelings (including "general feelings", see above) "pouring out of the lived body" (Stein 2008: 65, 117) of the other person are perceived exactly as not being mine, as contrasting to the 
original sensual pattern of feelings spreading out from my lived body in and by which the con-original feelings of the other person are perceived. This is what "con-original" means in the first step: general contrast of all sensual feelings belonging to me (originally perceived) versus to the other person (non-originally perceived). In the second step, however, my sensual feelings follow the sensual feelings of the other person through, and in this process con-original must mean a different thing than on step one, namely that my sensual feelings feel their way into the sensual field of the other lived body and I thereby experience a contrast between the same sort offeeling as had by me in contrast to being had by the other.

Already in the first step, the lived body of the other can appear to me as expressing a certain sort of feeling, like happiness in the example of tail-wagging. But in this step, the source of con-originality is not happiness as felt from my perspective in contrast to the original happiness of the dog. I may feel sad when I feel the dog to be happy (provided I am able to understand the expression of the dog as happiness), but when I proceed to step two (spontaneously) the con-original contrast becomes a contrast between my "following through" happiness and the dog's happiness that I follow. This does not mean that my whole field of sensual and general life feelings is transformed into happy con-original tail-wagging in step two (or other con-original waggling of the whole body if we presume that the tail is a problem here). Actually, the whole process depends on the first-step general contrast of my "egoish" sensual feelings and the appearance of the outer world's "ego foreign" sensations remaining in place to some extent, because otherwise the vicarious happiness would be devoid of any ego (self, person) performing the step-two empathy in question. On step three this general contrast is secured by returning to a position in which I perceive the expressive body of the other from my own rather than "from the other subject's place," as Stein puts it in the quote I gave above (Stein 2008: 19).

In sensual empathy I remain in my place having my experience, but I also follow the experience of the other person in front of me by being sucked into a field of sensations foreign to mine. At every step of the empathy process my sensual feelings and the sensual feelings of the other person remain distinct, but their way of contrasting to each other in yielding a subsequently fuller understanding of the other are different. Step three represents complexity of con-originality to an even larger extent: affectively understanding the dog to be happy while myself remaining sad but perhaps also sensing an influence of the vicarious tail-wagging on the general feelings that are related to my sadness.

I think these distinctions, which can be worked out through Stein's theory, are important to the criticism Dan Zahavi has levelled on simulation-based theories of empathy and the so called isomorphism criterion, for instance in the case of Frédérique de Vignemont and Pierre Jacob (Jacob 2012; Zahavi 2011). Zahavi, in accordance with theories found in Husserl and Scheler, takes empathy to be a direct perceptual experience of the other person in the everyday face-to-face encounter that does not include any attempts to simulate the empathee's condition (Zahavi 2014). A simulation theory of empathy appears to require that the empathizer has a feeling experience similar to the empathee's when empathizing, but, as Zahavi argues, do I not often understand the feeling of the other without having the same sort of feeling myself? Maybe, for instance, I become afraid upon seeing that the other person is angry, rather than becoming angry myself, but this does not mean that I do not understand what the other person is feeling (Zahavi 2011). 
Proceeding from Stein, Zahavi would be right in pointing out that the empathizer's perceptual understanding of the empathee does not rely in every case on developing the same sort of feeling that the empathee is having, provided we stay on the first step in her model. In step one I may understand that the other person is angry without being angry myself. Perhaps I am sad or happy or bored when he suddenly turns up. As a matter of fact, anger is a feeling that is particularly hard to empathize with because expressions of anger do not generally have the "in-pulling" tendency that we find in place, for instance, in pain or sadness (see the notion of "affective schemas" developed in: Svenaeus 2016). Instead anger has the general tendency to provoke either counteranger or escape behaviour in most mammals (including Homo sapiens).

To repeat, Zahavi claims that I may understand that the other person is angry without becoming angry myself, and this is certainly true for step-one empathy in which the connecting con-original contrast may involve various sorts of feelings on the part of the two parties. But the fact that step one in such a case does not lead to a step two and an ensuing, enriched step three does not mean that the situations in which step one does lead to steps two and three would not lead to a fuller understanding than step-one empathy does, and these situations would demand the empathizer to be in a similar sort of feeling as the empathee on step two (see also Dullstein 2013). As a matter of fact, such situations, in which the empathizer proceeds from step-one to step-two sensual empathy, do demand that the empathizer feels herself into the feelings of the empathee by having the same sort of feeling that the empathee has but in the con-original way (notwithstanding that Zahavi is right in pointing out that the exact meaning of "same sort" remains vague, also in Stein's model). Imagine a psychiatrist empathizing with the anger of a patient or a dog owner empathizing with the anger of her dog, of whom, for different reasons, they are not afraid. In both examples the encountered anger leads not to the standard reaction of fear and flight but to empathically felt anger on the part of the empathizer, and this is also the reason why, in these examples, we will have enriched understandings of the feelings of the empathees.

\section{Life force, drives, and contagion}

Stein does not discuss which features of sensual empathy are inborn and which are learned through experience. She often makes the point that she is not interested in explaining the phenomenon - a project that she takes many other empathy theorists to be busy with, for instance, Theodor Lipps - but in describing and understanding empathy from a phenomenological point of view (Stein 2008: e.g. 14, 21-22). However, one should not interpret Stein's phenomenological method as generally refraining from explanative accounts of what shows itself to us in lived experience, for instance, when we empathize with other human beings. Stein is clearly not uninterested in the empirical instantiations of that which Husserl referred to as pure consciousness (Husserl 1976); quite the opposite: her goal is rather to understand the coming together of nature and culture in a lived body that is simultaneously dependent on material processes and free to act. She refers to this as the contrast and unity between psychic (psychophysical) causality and spiritual ("geistige") motivation, a relationship that is in place already in her book on empathy but is explored in much more depth in Beiträge. As I view it, the relationship between sensual and what I 
have termed emotional empathy is precisely a relationship between these two domains of psychophysical causality and free will that are glued together by the feeling-experiencing body.

Sensual empathy, according to Stein, depends on sensual and life-bound general feelings "pouring out of" the lived body to be picked up and followed through by other lived bodies (Stein 2008: 65, 117). The concepts that Stein introduces in order to explain this outpouring quality of feelings in Beiträge are drive ("Trieb") and life force ("Lebenskraft") (Stein 2010: 5-109; see also Stein 2008: e.g. 55-56, 108-109).

There is no need to deem Stein a vitalistic thinker on account of the concept of life force, although one can assume that Wilhelm Dilthey and Henri Bergson were important for her in developing this concept (the two philosophers are mentioned and referred to several times in the empathy book as well as in Beiträge). However, when the concept is first introduced in Beiträge it is not Bergson's "élan vital" but Lipps's notion of "psychische Kraft" that is pointed to as a source of inspiration (Stein 2010: 22).

The drives or needs ("Triebe") are announcements made by the life force in the stream of experiences ("Erlebnisstrom") that make the lived body move and behave in a way that should ensure survival (Stein does not enter into the subject of reproductive drives) (Stein 2010: 57-61). Drives are experienced in sensual feelings through which I am drawn to or repelled by certain features of the world in a way that does not necessitate any decisions to act on my part in order for my body to move and behave (although I may to a certain extent refuse the movements and behaviours that the drives pull me towards). Stein does not go into any details here, but examples of drives that human and many other animal beings experience would be hunger, pain, fear, and sexual attraction. The "sphere of life" is described as a sub-layer of the stream of experience that makes up the life of each individual, and as such a sub-layer it provides the very force by which the stream moves forward temporally, a pull that is felt by way of the general life feelings and the drives (Stein 2010: 26-27).

It appears that sensual empathy should occur in accordance with similar life-force mechanisms that make themselves known in sensual feelings, general life feelings, and drives. In sensual empathy the feeling-based experience of seeing and following through a foreign lived-body experience is not perceived as a choice made by the empathizer; the steps of the empathy process progress as a result of the energetic drive of the life force. Today the processes underlying sensual empathy would be accounted for by features of brain activity, such as mirror neurons, rather than by life force, which is a dated and to some extent redundant concept. Nevertheless, Stein's attempt to understand the causal processes at work in feelings by way of life force shows her attempt to not only describe empathy but also understand its preconscious roots (Svenaeus 2016).

At this point, it becomes important to point out that sensual empathy, according to Stein, is not only an instance of "emotional contagion" ("Gefühlsansteckung"), a phenomenon that was already well known in her time. The reason the two phenomena are not identical is that the feelings had in going through sensual empathy are not originally ("originär", "leibhaft") experienced by the empathizer, as they are in emotional contagion, but instead are "con-original"; that is, they are given to the empathizer as belonging to the empathee. Consequently, the subject of emotional contagion is not an empathizer, since he is experiencing the feelings in question as his own feelings, unaware of their source (Stein 2008: 35-37). 
Stein thinks that emotional contagion is a process that in most situations presupposes empathy rather than the other way around. To put contagion first has been a common way to develop explanations of empathy in simulation-based theories (Iacoboni 2008). In such theories, the first well-known example is Theodor Lipps's, we are brought through preconscious contagion to a feeling state that resembles the state of the person we are perceiving. To make sense of this feeling we project it on the other person, and by this process we also empathize with him (Zahavi 2014). For Stein such a way of approaching the empathy process is wanting because it does not acknowledge the stepone understanding of empathy that is needed in order to proceed to step two (Stein 2008: 21-22, 27-28, 35-37). When I perceive the acrobat on the tightrope (Lipps's most famous example), I must first see that he is there, balancing on the rope, his lived body expressing certain sensual and life-based feelings by way of a sensual-perceptual field that contrasts to mine (Stein 2008: 27-28). In the second step, I then follow this sensual perceptual field that I am drawn into and only at this point do I con-originally experience the same sort of sensual feelings that he is having when balancing. The reason Stein is not only critical but also appreciative as concerns Lipps's empathy theory is exactly that she operates with two meanings of con-original in her empathy theory (if she had been more detailed and consistent on this point the reader would have been spared a lot of confusion). Lipps gets the con-original experience of step-two empathy right, but he does not acknowledge that this experience presupposes a different con-original experience of the acrobat in step one. He also, according to Stein (but she might well be wrong on this point, see Stueber 2006: 8), tends to confuse the going-with empathy in step two with a being-at-one ("Einsfühlung") with the acrobat in which the viewer and the viewed would merge into one experience. As we have seen, empathy in either step always presupposes that the experience of the empathizer is distinct from the experience of the empathee. This distinctiveness of two separate experiences also holds for other more mutual co-experiences, such as being happy together or taking action together (Stein 2008: 28-29), modes of cooperation that are analysed in much more detail in the second part of Beiträge (Stein 2010: $163 \mathrm{ff}$.).

In summing up Stein's views on emotional contagion one should mention that she does not rule out cases in which I would be influenced by the emotional expressions of other people, or other features of the environment, without taking notice and would consequently end up with a corresponding feeling without being aware of other people or other mood-expressing qualities of the world influencing me in this way (Stein 2008: 37, 38-49, 89-90). In Beiträge Stein analyses the processes of emotional contagion in much more detail and comes to the conclusion that we have three different possibilities as regards its relationship to sensual empathy (Stein 2010: 155-156). We may, firstly, have emotional contagion without comprehension of the source, and in these cases the causal influence relies on the way "egoish" (body-bound) sensual and general feelings connect to their "ego foreign" sources without making them appear as conscious objects to us. In such cases the source of our changed feelings may be not only other people but also, for instance, expressive qualities of music or a landscape. We may, secondly, have emotional contagion with comprehension of the source when the process behind contagion described above also has the effect of making the source stand out from its surroundings, drawing us into its presence. The second case would be an instance of step-one empathy in the process of developing into step-two empathy 
when the source of transformation of our feelings is another lived body. And we may, thirdly, have empathic comprehension of a thing in the world standing out to us without any perceived contagion going on. The third case would be an instance of step-one empathy when the comprehended thing is another living being. When the first step is followed by the second step in the empathy process, we have a transformation from the first to the second sense of con-originality in the sensual feeling pattern of the empathizer. Although such sensual empathy does not depend on emotional contagion in the first step, it does depend on something similar to contagion in the second step, since the perceived urge to share the sort of feeling expressed by the empathee is a part of the empathic experience. As I discussed above, cases of first-step sensual empathy that do not proceed to step two are prevented from doing so by other feeling-reactions that the empathizer has or by the empathizer's resisting the pull of the feeling of the empathee.

How can the feeling of empathy be partly an effect of forces beyond consciousness and still be an experience with a meaning content that expresses knowledge of another person? The clue to understanding how sensual, body-based feelings in Stein's theory proceed to reveal knowledge of the other person is to make explicit how the empathy experience despite, or, rather, precisely by, being rooted in feelings may carry cognitive content of various depth on different levels.

\section{Emotional empathy and sympathy}

In sensual empathy I become aware that the other person is there as a lived body in front of me, and, also, that she has a certain sort of feeling. I feel the tense, pressing tendency of the hand on the table and I feel the sadness of the other person expressed in her face (Stein 2008: 18-19, 75). But I do not yet feel and understand why the hand is tense and pressing against the table or why the person is sad. When the empathizer, by way of the empathy process and other knowledge about the empathee, also understands what the object of the empathee's feeling is, the empathy in question has been transformed from being merely sensual into what I would like to call a case of emotional empathy. Step-three sensual empathy is then transformed into a first step in the process of emotional empathy (perhaps it is also possible in some cases to transform step-one sensual empathy directly into a first step of emotional empathy). At this point, for Stein, empathy proceeds into the dimension of what she calls spirit ("Geist"), a transformation that is best captured not by references to religious beliefs but to emotions in the contemporary philosophical sense. Emotions, in the contemporary sense, are, precisely, feelings that have objects, feelings that are about things in the world, which they present in a certain evaluative light (Goldie 2000). Empathy is a feeling about feelings (sensual empathy) that can become an emotion about emotions (emotional empathy).

As becomes obvious in Stein's discussions of different types of feelings, the borderline between feelings that merely have an experiential quality and the feelings that also have a meaning content by being about things in the world (including other persons in the world, such as happens in empathy) is not absolute but gradual. Sensual feelings, such as thirst, make themselves known not only in a feeling thirsty but also as directing this feel towards certain objects in the world as being desirable, such as water. 
Already in sensual empathy the feeling experienced by the empathizer could be said in a minimal sense to be an emotion, since the empathizer's feeling is about the empathee's feeling as being such and such, rather than just being a feeling influenced by the feeling of the empathee. The empathizer's feeling is non-original, or, more precisely, con-original, instead of original, in the terminology used by Stein.

That which Stein, in proceeding from the phenomenology of Husserl, calls the "Gehalt" of an experience always has two components, the "way of being given" ("Gegebenheitsweise") and the "what is being given" ("Gegenstand"), where the latter is also called the object of the experience (Stein 2008: 15-16; Stein 2010: 18-19, 8687). "Gehalt" can be translated as "content" or "meaning content", as I have done above, but it is consequently important to remember that to the content, in the sense of a "what is being given", there always belongs a "how it is being given". However, in sensual feelings, like being thirsty, the contrast between the way something is presented and what is being presented appears only as a difference between what Stein calls "egoish" and "ego foreign" aspects of the experience (see above) and not in terms of "Gegebenheitsweise" and "Gegenstand". The "egoish" aspect is the how and the "ego foreign" aspect is the what of what is being experienced in sensual feelings, but this what is not yet a specific meaning-content-object but is rather an object which the how of the experience is in search of. In the case of drives this is particularly obvious, but, as I have tried to make clear above, in all forms of feeling-based sense perception (including sensual empathy) the perceiver feels a certain "stimulation" ("Reiz") that attracts him towards the object, or, rather, attracts him towards what becomes an object precisely by way of this attracting force (Stein 2010: e.g. 41-42).

In emotional empathy the feeling-alongside that takes place in step two is extended in that it concerns not only the sort of feeling the empathee is having but also what the object of this feeling is. This can happen in different ways: perhaps I am already aware of things that have happened to the empathee that make me understand what must be (or, rather, what is likely to be) the object of her feeling; or perhaps the expression of the feeling that the empathee is having makes me look for the reason in the things that appear in her nearby environment. In order for this "looking for the reason" to count as empathy, the reason should be found by following the experience through and not by way of a conclusion. I exercise empathy if I find the object of the empathee's emotion by following her gaze when she laughs at the stumbling clown, but I do not exercise empathy if I conclude from seeing a sweepstake ticket on the table beside her that she is probably happy because she won the lottery.

The stumbling-clown and the sweepstake-ticket joys are my examples, not Stein's, and, indeed, she does not give many examples of how the object of an emotion is given with the expression ("Ausdruck") of the empathee (Stein 2008: 68-74). The reason for this is probably that she takes the complexity of that which she calls "spiritual feelings" (Stein 2008: 66), or "feelings in the pregnant sense of the word" (Stein 2008: 119), to encompass objects that are impossible to detect and understand just by following the gazes or action tendencies of the empathee. Let me go through the way she presents the relationship between feeling about a certain event (a variant of the object"Gegenstand" - an emotion takes on) and the empathic feeling alongside the person, who is the subject of this happening (Stein 2008: 23-25):

My friend comes into the room and tells me, full of joy, that she has passed her exam. Already before I have comprehended what she says I sensually empathize that 
she is entering the room and is happy. I then understand what she says and I also, immediately following this comprehension, feel my way into her joy and understand it to be about her passing the exam (emotional empathy). As a result of this, I do not just feel and understand that she is happy and why; I also, because I care for her, become happy myself for the reason that she has passed the exam. Now, this situation, at first glance rather straightforward and simple, is, as Stein shows, rather complex. There exist multiple ways of sharing the joy and ending up feeling happy about the friend's having passed the exam.

For example, I may not only comprehend but also feel happy about the event just by being told that she has passed the exam. I may then turn my attention towards her expressed experience and empathize with it, and as a result of this still feel happy about the fact that she has passed the exam but in a way that also follows and goes with her joy. In Stein's theory, only this way of being happy about the friend counts as the phenomenon that is known as compassion or sympathy ("Mitfühlen") (Stein 2008: 25). That is, it is not enough that I feel with the friend in the sense of caring for her and therefore feel happy about her success when told about it; I must also pass through the process of emotional empathy in order for the sympathy to be in place. This is an understanding of sympathy that is different from the standard one in contemporary empathy research in which compassion in the sense of caring for the other without empathizing with her would also count as sympathy.

The reason Stein makes this qualification of sympathy is probably that she takes the very process of feeling one's way into the feelings of other persons to be absolutely essential to our formation as social and ethical creatures (Calcagno 2014). Nevertheless, one should be aware that this understanding of sympathy is potentially confusing, since Stein in her empathy book often uses the preposition "with" ("bei," "mit") in combination with a feeling process in characterizing step-two empathy, which can but does not necessarily lead to sympathy (eg. Stein 2008: 18-20, 31, 101). I may end up happy after having fulfilled the process of empathically feeling the happiness of my friend, but the reason for my end-state happiness may be that I will be able to accomplish something that $I$ want - for instance, a journey together with my friend - rather than my being happy about the passed exam for the friend's sake (Stein 2008: 25). If the person who has passed the exam is not my friend, but my enemy, the process of empathizing with her may not be enough to turn my hostility into sympathy, since I will still be angry and disappointed about her passing for the reason of disliking her. And, if she is my enemy and fails the exam, the feeling I will develop through the empathy process will probably be something like "Schadenfreude", which would be strange to characterize as sympathy.

In discussing the friend-passing-the-exam example Stein makes perfectly clear that she sees the difference between sympathy and empathy to lie exactly in that the feelings of the two parties in the latter case are always the same sort of feeling, having the same content, with the qualification that the empathizer is experiencing the feeling in a nonoriginal way in comparison with the empathee. Sympathy, "Mitfühlen", on the other hand, writes Stein, can be different in content from the feeling the empathee has (Stein 2008: 25). Say, for instance, that the friend is mistaken and thinks she has failed the exam (by way of misreading the results posted on the board). If I know from having read the results myself (without making any mistakes) that she has actually passed the exam, I may empathize with her disappointment and feel sympathically happy about 
her actually having passed before telling her the good news. Although such ways of feeling with and for the other person are not cases of sharing in the strict sense of having the same feeling or having it together with the other person, they are crucial ways of connecting to a specific other and coming to care for her (Zahavi and Rochat 2015).

\section{Empathy and ethics}

With Stein's version of sympathy we have definitely become involved in answering the second question of empathy research that I referred to above, namely, "What leads one person to respond with sensitivity and care to the suffering of another?" (Batson 2009: 3 ). To spell out the full answer to this question from Stein's philosophy goes well beyond what I am capable of in this paper (see Calcagno 2014; MacIntyre 2007), but I will try to offer some relevant concepts and arguments that Stein refers to in linking her empathy theory to topics in moral philosophy.

One should note that, according to Stein, morally relevant feelings are at work already in sensual empathy. As we have seen, the bodily expressions of the other person draw me into her presence and by way of this process I not only attend to but also spontaneously follow her experiences through. This means that if the other is suffering in front of me, I will acknowledge this in the manner of feeling along with her and will possibly also sympathize with her and attempt to help her as a result of this. This sensitivity to emotional expressions of other living creatures is partly inborn, but the way we cultivate this sensitivity will certainly depend on early experiences and the way we are taught to embrace or reject others (Rochat 2009). To be empathic in the meaning of being sensitive to the feelings of the other person is consequently a skill that can be taught and which rests on taking a fundamental interest in her feelings. It appears that some psychiatric disorders like autism and psychopathy are due to a lack of sensitivity to or interest in the experiences of the other person (Baron-Cohen 2011; Svenaeus 2015).

Stein does not distinguish feelings only as operating at a sensual or emotional level of depth; they can also be distinguished as regards duration, reach, and intensity (Stein 2008: 122-123, see also Vendrell Ferran 2015). Feelings can last for a longer or shorter time, they can encompass more or less of the experienced world of the person, and they can be more or less intense in nature. As regards intensity, Stein introduces the life-force mechanism to explain why certain feelings are felt with more or less energy (Stein 2010: 57-61). The difference between sensual and general feelings, which are mainly bodily in nature, and the feelings that are "spiritual" and which I have termed emotions is a difference in what Stein calls "depth" (Stein 2008: 122). The depth of a feeling shows itself through its content-how complex the matters are that are being understood by way of the emotion - and increased complexity implies that the life of a person is involved and not only the drives that govern her body. The contents of emotions relate to the hierarchy of values that Stein takes to be present in the world of persons. Stein is an emotional value realist, and this means that what we ought to be and do shows itself to us through the feelings we develop in encountering the experiences and actions of other persons (she is clearly influenced by Scheler in this area, see Scheler 2009). 
Several things need to be articulated in order to make sense of Stein's philosophy of feelings in relationship to ethics, and I will only be able to make a sketch here. My aim is not to defend her (to a large extent rather underdeveloped) moral philosophy, but rather to make it intelligible for the purpose of better understanding her theory of empathy.

According to Stein every feeling has a value component to it, since it judges a state to be good or bad for the subject in various ways. On the level of sensual feelings this goodness or badness is merely about feeling good or bad in a bodily manner. When a feeling is developed into an emotion, the judging in question is not only about a bodily state but also about a state of (object in) the world. When I feel happy about my friend's having passed the exam I value the fact that she has passed, and when I feel bad about not having passed the exam myself I disvalue the fact of not passing. In the latter case the feeling of badness can be more complex if I have a bad conscience because of not having studied hard enough before the exam, and even more so if I take myself to be worthless and deserving punishment for not studying and/or passing.

To make things even more complex, the value hierarchy means that we can be right or wrong when we have a certain emotion (Stein 2008: 114-115, 119-121, 126). If, for instance, a possibility for action opens up through an emotion in which we understand that the other person should be loved and helped and we do not feel or do this, we are not responding in the correct way to the values that are present. Furthermore, each person, according to Stein, has a certain preformed character, which she can attend to and develop or neglect. This "root" or "seed" of the personality Stein calls "Persönlichkeitskern" and she elaborates in even more detail in Beiträge how it can and should be developed if we are to live an authentic and morally excellent life together (Stein 2008: 121-130; Stein 2010: 80, 166-167, 191-194). Consequently, according to Stein's theory of value and personality, that a feeling has depth means that it stretches deep into the character of the person it concerns and displays moral knowledge of how to act and develop oneself.

In the case of empathy, the character to which we should attend is not only our own but also that of the other person, which shows itself to us in the feelings she expresses in and through her actions (Stein 2008: 127; Stein 2010: 196). Consequently, what we get acquainted with through empathy is not only sensual feelings or emotions but also the personality of the person who is having the feelings in question. We need to get to know the personality of the other person if we are to be able to follow and understand her experiences in depth and, as a result of this, develop her and our own character in a way that accords with the hierarchy of ethical values (Stein 2008: 134-135). As a source of energy in this emotional process, which prescribes the way emotional experiences are expressed and turned into actions, we have not only the bodily life force discussed above but also a "spiritual life force" ("geistiger Lebenskraft") (Stein 2010: 69-75, 99). The spiritual life force is the energy that fills us when we feel something to be noble and/or the right thing to do in a certain situation. The energy for feeling and acting in the right way is accordingly offered in two complementary ways: through bodily-based feelings and through emotions that target spiritual values. In cases in which we fail to feel and do the right thing our deficient experiences and actions can be due to lacks in one or both of these domains of psychic power. 


\section{Conclusion}

In this paper I have presented the phenomenology of empathy that we find in the early works of Edith Stein and tried to make its main features lucid. I have done this by making explicit two different aims that are implicit in Stein's theory, namely to understand how we get to know the experiences of other persons and how this knowledge may guide us in treating them with care. The clue to understanding how the different features of and aims behind Stein's empathy theory hold together is, I have claimed, to stress that empathy is a feeling of the other person's feeling, or, rather, a set of such related feelings about the state of the other. Empathy, according to Stein, is a feeling of being touched by and following in the footsteps of the feeling of the other person in a three-step process on two interrelated levels here named sensual and emotional empathy.

The feeling had by the empathizer is a feeling had in a "con-original" way, meaning that the feeling in question presents the feeling of the empathee, first in general contrast to the empathizer's own feelings (step one), and then as the same sort of feeling but had in an attempt to follow the feeling of the empathee through (step two), returning to an enhanced feeling-based understanding of the empathee's feeling (step three). The basic, bodily empathy process, which Stein calls sensual empathy, is at work in all cases of empathy, but in some such cases empathy may stop on step one because the whole contrasting set of feelings, which makes the feeling of the empathee stand out, directs the emotional attention of the empathizer in other ways and/or because the empathizer is able to resist by way of will the pull into step-two empathy. Empathy is a feeling of the other person's feeling that may develop into an emotion about the other person's emotion and her personal way of being in the world. In such cases empathy becomes emotional in type, not only in the minimal sense of being about the empathee's feeling, but by being about the object of the empathee's feeling, which is consequently, in such cases, also an emotion.

Empathy in all forms, according to Stein, has a sensual basis, but it is enlarged and deepened by way of knowledge about the state of the empathee and by way of the empathizer's following the experiences of the empathee through. By the act of conoriginally feeling with the empathee and getting to know more about him, empathy often result in sympathy or in some other way of being concerned about the empathee. Empathy may also result in and/or be a part of other forms of feeling and acting together in the world that are mutually attentive. In such forms of we-intentionality, according to Stein, the co-operators remain distinct with regard to their experiences, but yet have a shared sense of feeling and/or doing the same thing. Empathy, in contrast to this, in Stein's model, remains one-way other-directed, yet as this unique and special form of experience provides a peculiar feeling of being-with the empathee and sharing his predicament that can be used to enhance our understanding of others and feel for them in various ways. This emotional understanding of the other is also the road to deepened knowledge about myself in Stein's theory, something that, in turn, is an integrated part of her entire value- and feeling-based social and moral philosophy.

Acknowledgements I want to thank Matthew Ratcliffe, Line Ryberg Ingerslev, Oliver Lukitsch, Christoph Durt and others in the Phenomenological Psychopathology and Philosophy of Psychiatry research group at the 
University of Vienna for stimulating discussions about the phenomenology of empathy and two anonymous reviewers for essential feedback allowing me to present Stein's theory in a more lucid and relevant manner.

Open Access This article is distributed under the terms of the Creative Commons Attribution 4.0 International License (http://creativecommons.org/licenses/by/4.0/), which permits unrestricted use, distribution, and reproduction in any medium, provided you give appropriate credit to the original author(s) and the source, provide a link to the Creative Commons license, and indicate if changes were made.

\section{References}

Baron-Cohen, S. (2011). The science of evil: On empathy and the origins of cruelty. New York: Basic Books. Batson, C. D. (2009). These things called empathy: Eight related but distinct phenomena. In J. Decety \& W. Ickes (Eds.), The social neuroscience of empathy (pp. 3-15). Cambridge: MIT Press.

Calcagno, A. (2014). Lived experience from the inside out: Social and political philosophy in Edith Stein. Pittsburgh: Duquesne University Press.

Colombetti, G. (2014). The feeling body: Affective science meets the enactive mind. Cambridge: MIT Press.

Coplan, A., \& Goldie, P. (2011). Introduction. In A. Coplan \& P. Goldie (Eds.), Empathy: Philosophical and psychological perspectives (pp. ix-xlvii). Oxford: Oxford University Press.

de Vignemont, F. \& Jacob, P. (2012). What is it like to feel another's pain? Philosophy of Science, 79(2), 295-316.

Decety, J. (Ed.). (2012). Empathy: From bench to bedside. Cambridge: MIT Press.

Dullstein, M. (2013). Direct perception and simulation: Stein's account of empathy. Review of Philosophy and Psychology, 4, 333-350.

Goldie, P. (2000). The emotions: A philosophical exploration. Oxford: Oxford University Press.

Goldman, A. I. (2006). Simulating minds. New York: Oxford University Press.

Husserl, E. (1976). [1913]. Ideen zu einer reinen Phänomenologie und phänomenologischen Philosophie. Buch 1: Allgemeine Einführung in die reine Phänomenologie. The Hague: Martinus Nijhoff.

Iacoboni, M. (2008). Mirroring people: The new science of how we connect with others. New York: Farrar, Straus \& Giroux.

Jardine, J. (2014). Husserl and Stein on the phenomenology of empathy: Perception and explication. Synthesis Philosophica, 58(2), 273-288.

Jardine, J. (2015). Stein and Honneth on empathy and emotional recognition. Human Studies, 38, 567-589.

MacIntyre, A. (2007). Edith Stein: A philosophical prologue. Lanham, Maryland: Rowman \& Littlefield.

Ratcliffe, M. (2008). Feelings of being: Phenomenology, psychiatry and the sense of reality. Oxford: Oxford University Press.

Rochat, P. (2009). Others in mind: Social origins of self-consciousness. Cambridge: Cambridge University Press.

Scheler, M. (2005) [1913/23]. Wesen und Formen der Sympathie. Gesammelte Werke Bd. 7, Bern: Francke Verlag.

Scheler, M. (2009) [1913/16]. Der Formalismus in der Ethik und die materiale Wertethik: Neuer Versuch der Grundlegung eines ethischen Personalismus. Gesammelte Werke Bd. 2, Bern: Francke Verlag.

Stein, E. (2008) [1917]. Zum Problem der Einfühlung. Gesamtausgabe Bd. 5, Freiburg: Verlag Herder.

Stein, E. (2010) [1922]. Beiträge zur philosophischen Begründung der Psychologie und der Geisteswissenschaften. Gesamtausgabe Bd. 6, Freiburg: Verlag Herder.

Stueber, K. R. (2006). Rediscovering empathy: Agency, folk psychology, and the human sciences. Cambridge: MIT Press.

Svenaeus, F. (2015). The relationship between empathy and sympathy in good health care. Medicine, Health Care and Philosophy, 18(2), 267-277.

Svenaeus, F. (2016). The phenomenology of empathy: A Steinian emotional account. Phenomenology and the Cognitive Sciences, 15(2), 227-245.

Szanto, T. (2015). Collective emotions, normativity and empathy: A Steinian account. Human Studies, 38, 503-527.

Vendrell Ferran, I. (2015). Empathy, emotional sharing and feelings in Stein's early work. Human Studies, 38, 481-502.

Zahavi, D. (2011). Empathy and direct social perception: A phenomenological proposal. Review of Philosophy and Psychology, 2, 541-558.

Zahavi, D. (2014). Empathy and other-directed intentionality. Topoi, 33(1), 129-142.

Zahavi, D., \& Rochat, P. (2015). Empathy $\neq$ sharing: Perspectives from phenomenology and developmental psychology. Consciousness and Cognition, 36, 543-553. 